\title{
REVIEW ARTICLE Caffeine: an evidence-based success story in VLBW pharmacotherapy
}

\author{
Nicole R. Dobson ${ }^{1}$ and Carl E. Hunt ${ }^{1}$
}

Apnea of prematurity (AOP) is a common and pervasive problem in very low birth weight infants. Methylxanthines were reported $>40$ years ago to be an effective therapy and, by the early 2000 s, caffeine had become the preferred methylxanthine because of its wide therapeutic index, excellent bioavailability, and longer half-life. A clinical trial to address unresolved questions and toxicity concerns, completed in 2004, confirmed significant benefits of caffeine therapy, including shorter duration of intubation and respiratory support, reduced incidence of chronic lung disease, decreased need for treatment of patent ductus arteriosus, reduced severity of retinopathy of prematurity, and improved motor and visual function. Cohort studies have now further delineated the benefits of initiation of therapy before 3 days postnatal age, and of higher maintenance doses to achieve incremental beneficial effects. This review summarizes the pivotal and in particular the most recent studies that have established the safety and efficacy of caffeine therapy for AOP and other respiratory and neurodevelopmental outcomes. Caffeine has a very favorable benefit-to-risk ratio, and has become one of the most prescribed and cost-effective pharmacotherapies in the NICU.

Pediatric Research (2018) 84:333-340; https://doi.org/10.1038/s41390-018-0089-6

\section{INTRODUCTION}

Apnea of prematurity (AOP) is defined as cessation of breathing for longer than $20 \mathrm{~s}$, or respiratory pauses of shorter duration with associated bradycardia or oxygen desaturation. ${ }^{1}$ AOP is inversely related to gestational age; more than $85 \%$ of infants born at $<34$ weeks and $100 \%$ of infants born at $<28$ weeks gestation exhibit AOP-related symptoms due to immaturity of the brainstem and peripheral chemoreceptors. ${ }^{2}$ AOP is thus a common and pervasive problem encountered in the newborn intensive care unit (NICU). Interventions for AOP include tactile stimulation, nasal cannula flow or continuous positive airway pressure, positive pressure ventilation, and methylxanthine therapy. Methylxanthines have been used for $>40$ years to treat AOP in the NICU. This review focuses on: (1) how and why caffeine has become one of the most commonly prescribed and cost-effective pharmacotherapies for very low birth weight (VLBW) infants $(<1500 \mathrm{~g})$ in the NICU; (2) its favorable benefit-to-risk profile; and (3) new insights and unresolved mechanisms or issues.

\section{HISTORY OF METHYLXANTHINE USE}

The first methylxanthines used for AOP were aminophylline and theophylline, and the initial studies documenting efficacy were published $>40$ years ago. ${ }^{3-5}$ The major metabolite of the dimethylxanthine theophylline in neonates is caffeine, a trimethylxanthine. Caffeine has more potent central activity and less peripheral effects than theophylline. There is significant variability in the elimination of caffeine with a half-life of $40.7-231 \mathrm{~h}^{6}$ A pharmacokinetic study confirmed the longer half-life, excellent oral bioavailability, and wide therapeutic index of caffeine, with levels as high as $84.2 \mu \mathrm{g} / \mathrm{ml}$ tolerated by preterm infants with minimal side effects. ${ }^{7}$ Collectively, these early studies showed that caffeine was an effective pharmacotherapy for AOP. A caffeine citrate loading dose of $20 \mathrm{mg} / \mathrm{kg}$ followed by a $5 \mathrm{mg} / \mathrm{kg}$ daily maintenance dose resulted in plasma concentrations of 5-20 $\mu \mathrm{g} /$ $\mathrm{ml}$ and seemed generally sufficient to alleviate clinical symptoms. ${ }^{6}$

The use of methylxanthines had increased dramatically by the 1990 s, but the efficacy and safety of caffeine therapy in VLBW infants remained controversial. To address these controversies, the Caffeine for Apnea of Prematurity (CAP) Trial was established. ${ }^{8}$ This multi-site trial enrolled 2006 infants weighing $500-1250 \mathrm{~g}$ at birth. Infants were randomized to caffeine or placebo within the first 10 days, and the treatment continued until no longer clinically necessary. The caffeine cohort received a loading dose of $20 \mathrm{mg} /$ $\mathrm{kg}$ of caffeine citrate and an initial maintenance dose of $5 \mathrm{mg} / \mathrm{kg} /$ day. The median age at initiation of treatment was 3 days (interquartile range [IQR] 2-5), the median duration of therapy was 37 days (IQR 24-46), and the median postmenstrual age (PMA) at last dose was 34.4 weeks (IQR 33.0-35.9). ${ }^{8}$ The CAP Trial did not have independent data monitoring, but the investigators performed extensive central monitoring at the data center, including source document verification of all Bayley test results (a primary outcome) and correction of administrative, scoring, and reporting errors as needed to ensure the accuracy of results prior to final data entry. ${ }^{9}$ The results of this clinical trial, including follow-up to age 11-12 years, are summarized in the following sections.

\section{MECHANISMS OF ACTION}

Methylxanthines act both peripherally and centrally through antagonism of adenosine $\mathrm{A} 1$ and $\mathrm{A} 2 \mathrm{~A}$ receptors to stimulate the medullary respiratory centers (Table 1 ). This stimulation increases sensitivity to carbon dioxide, improves sensitivity and/

${ }^{1}$ Department of Pediatrics, Uniformed Services University of the Health Sciences, Bethesda, MD, USA

Correspondence: Nicole R. Dobson (Nicole.dobson@usuhs.edu)

Received: 1 October 2017 Revised: 22 March 2018 Accepted: 14 April 2018

Published online: 9 July 2018 
Table 1. Mechanisms of action of caffeine administration

\begin{tabular}{|c|c|c|}
\hline Action & Biochemical effect & Clinical effects \\
\hline $\begin{array}{l}\text { Inhibits cyclic nucleotide } \\
\text { phosphodiesterase }\end{array}$ & Increases the concentration of CAMP & Modulates inflammation \\
\hline
\end{tabular}

or responsiveness to $\mathrm{PaO}_{2}$, enhances diaphragmatic function, and induces bronchodilation. These effects lead to increased minute ventilation related to increased inspiratory drive, with little effect on duration of inspiration or expiration, fewer apneas, and reduced hypoxic respiratory depression. ${ }^{10-15}$

Blocking adenosine receptors causes important secondary effects on multiple neurotransmitters, including noradrenaline, dopamine, serotonin, acetylcholine, glutamine, and gammaaminobutyric acid (GABA). ${ }^{12}$ Adenosine is critical for maintaining ATP levels in the brain, and adenosine levels increase dramatically during hypoxia and inflammation. Activation of adenosine A1 receptors protects against brain damage during hypoxic-ischemic injury in animal models. ${ }^{16-18}$ Since preterm infants often experience hypoxic-ischemic insults, concern persisted that caffeine may be detrimental to the developing brain, and therefore have long-term adverse neurodevelopmental consequences. The CAP Trial was designed to address this concern.

\section{CLINICAL EFFECTS OF THE TREATMENT}

Apnea of prematurity

The efficacy of caffeine in treating apnea was first demonstrated in 18 preterm infants with recurrent apnea, in whom the mean frequency of apneic spells decreased significantly. ${ }^{6}$ Studies comparing caffeine to theophylline and aminophylline showed equivalent effects, and a Cochrane review of six trials concluded that all methylxanthines were effective in reducing the frequency of apneic events. ${ }^{19-23}$ The better safety profile of caffeine, however, led the Cochrane authors to conclude that caffeine was the "preferred drug" for treating AOP. Evolving treatment patterns followed this recommendation, and exclusive use of caffeine in VLBW infants increased from $26 \%$ of all methylxanthine use in 1997 to $96 \%$ in $2010 .^{24}$

Caffeine is now universally considered to be effective in reducing apnea-related symptoms caused by immature autonomic control of breathing, but randomized clinical studies of methylxanthines for apnea prevention have had mixed results. One study of 50 spontaneously breathing preterm infants randomized to caffeine or placebo at $48 \mathrm{~h}$ of age did not show any benefit to prophylactic caffeine in reducing the number of hypoxemic episodes. ${ }^{25} \mathrm{~A}$ small trial assessing prevention of apnea in infants born $<33$ weeks gestation showed that caffeine prophylaxis reduced apnea in infants during the first week of therapy, but not thereafter. ${ }^{23}$ A systematic review concluded that the available evidence did not support the use of methylxanthine prophylaxis to prevent apnea in preterm infants. ${ }^{26}$ Nevertheless, prophylactic use of methylxanthines for apnea of prematurity is now common, with $62 \%$ of neonatologists reporting prophylactic use in an international survey. ${ }^{27} \mathrm{~A}$ recent small randomized trial did show that caffeine was effective in preventing apnea in very preterm infants in the first 10 days of life. ${ }^{28}$

\section{Extubation and bronchopulmonary dysplasia}

Methylxanthines are also often used in the NICU to facilitate extubation. The Cochrane review of prophylactic methylxanthine treatment to facilitate weaning from mechanical ventilation and extubation concluded that treatment reduced failure of extubation within 1 week. ${ }^{29}$ The mechanisms for improved extubation success rates are not fully delineated, but may in part be related to decreased respiratory system resistance, increased respiratory muscle strength, and improved functional residual capacity and compliance. ${ }^{30}$ In addition, a recent study using transcutaneous diaphragm electromyography showed that caffeine resulted in a rapid and sustained increase in diaphragmatic activity and tidal volume. ${ }^{31}$

In the CAP Trial, caffeine treatment was associated with 1 week less of endotracheal intubation, positive pressure ventilation, supplemental oxygen, and less use of postnatal steroids for lung disease. $^{8}$ The respiratory benefits included a reduction in the rate of bronchopulmonary dysplasia (BPD) (36.3\% with caffeine vs. $46.9 \%$ in the placebo group, $p<0.001)$. Follow-up at 11 years of 142 children enrolled in the CAP Trial showed higher expiratory flow and fewer children with forced vital capacity below the fifth percentile with caffeine compared with placebo treatment. ${ }^{32}$ As discussed in later sections, earlier initiation of caffeine treatment and higher doses may be even more effective in extubation success and reduced BPD rates.

In summary, caffeine treatment decreases extubation failure and risk for BPD. The mechanism for these benefits is related at least in part to fewer AOP-related symptoms, but improved diaphragmatic function and less bronchoconstriction are likely also contributing factors. Animal studies also suggest that the beneficial effects of caffeine on the neonatal lung may be related to reduced inflammation and protection from hyperoxia-induced 
damage by improving eNOS, ${ }^{33}$ and in vitro studies show that caffeine has anti-oxidant properties. ${ }^{34-36}$

\section{Neurodevelopmental outcome}

The primary outcome of the CAP Trial was a composite of death, cerebral palsy $(\mathrm{CP})$, cognitive delay, deafness, or blindness at a corrected age of 18-21 months. This outcome occurred more frequently in the placebo group $(46.2 \%)$ than the caffeine group $(40.2 \%, p=0.008) .{ }^{37}$ Caffeine also reduced the individual rates of $\mathrm{CP}$ and cognitive delay. There were no differences in rates of death, severe hearing loss, or bilateral blindness. Infants receiving respiratory support at enrollment seemed to derive more neurodevelopmental benefits than infants not receiving the support. ${ }^{38}$ Since caffeine-treated infants had improved outcomes at lower cost, caffeine treatment was concluded to be costeffective. $^{39}$ At 5 -year follow-up for CAP enrollees, there were no differences in rates of cognitive deficits and $\mathrm{CP}$ between the two groups; but among the subgroup of infants with $\mathrm{CP}$, the overall function on the Gross Motor Functional Classification System was improved in the caffeine group $(p=0.006){ }^{40}$ Moreover, the caffeine group experienced lower rates of developmental coordination disorder and motor dysfunction not associated with $\mathrm{CP}$ or cognitive impairment. ${ }^{41-43}$

At 11-12 years of age, the caffeine group had significantly less motor impairment compared with the placebo group $(19.7 \%$ vs. $27.5 \%$ in the placebo group, $p=0.009) .{ }^{44}$ These longer-term outcomes have thus confirmed that caffeine therapy is associated with sustained reductions in motor impairments.

Although fewer AOP-related events and less intermittent hypoxia may have contributed to improved neurodevelopment, this was not assessed in the CAP Trial. ${ }^{45-48}$ Only $50 \%$ of the neurocognitive benefits of caffeine at 18-21 months could be explained by improved pulmonary outcomes, suggesting a direct neuroprotective effect. In a subset of 70 CAP enrollees, assessment at term equivalent age (TEA) using quantitative magnetic resonance imaging (MRI) showed improved white matter microstructural development in caffeine-treated compared with placebo-treated infants. ${ }^{49}$ In a different study of perinatal antecedents of microstructural injury in extremely premature infants at TEA, longer duration of caffeine treatment was associated with less white matter injury. ${ }^{50}$ Caffeine also increases cerebral cortical activity in preterm infants, but it is unclear whether this represents a neuroprotective response ${ }^{51}$ (also see sections on early treatment and higher doses).

Animal studies generally support a direct neuroprotective effect of caffeine in the developing brain. ${ }^{52-56} \mathrm{~A}$ recent study showed that caffeine had a pleiotropic neuroprotective effect in the developing brain of rat pups due to its anti-oxidant, antiinflammatory, and anti-apoptotic properties. ${ }^{57}$ Other studies, however, have shown detrimental changes within the developing brain after caffeine exposure. ${ }^{58}$ These differing results are likely impacted by the species examined, caffeine dose used, neurodevelopmental stage at the time of administration, and duration of exposure. Moreover, animal models cannot account for the interactions between caffeine and other therapies in the NICU that may affect neurodevelopmental outcomes. ${ }^{58}$

\section{Retinopathy of prematurity}

In the CAP Trial, there was no difference in the rates of retinopathy of prematurity (ROP) between the treatment groups at NICU discharge. ${ }^{8}$ However, at 18-21 months, there was a trend toward lower rates of all stages of ROP in the caffeine-treated compared with placebo infants (39.5\% vs. $43.7 \%, p=0.06)$, and caffeinetreated infants had less severe ROP, $5.1 \%$ in the caffeine group compared with $7.9 \%$ in the placebo group $(p=0.01) .{ }^{37}$ Although the shorter duration of positive airway pressure and supplemental oxygen in caffeine-treated infants may have contributed to the reduction in severe ROP, intermittent hypoxia has also been associated with severe ROP and caffeine decreases the extent of intermittent hypoxia. ${ }^{45,46,48}$

Animal studies provide some insights into potential mechanisms by which caffeine ameliorates ROP. Adenosine subtype receptors in the retina modulate inflammation, neuroprotection, and angiogenesis, and a therapeutic benefit of caffeine for ROP appears to be supported by its ability to control angiogenic factors such as hypoxia inducible factor-1a and vascular endothelial growth factor (VEGF), angiogenesis, apoptosis of endothelial cells, and other vascular actions..$^{59,60}$ In a rat pup model of ROP, both caffeine and a non-steroidal anti-inflammatory drug given alone reduced retinal neovascularization, but when given together, appeared to prevent severe retinopathy related to effects on retinal and serum growth factors, including insulin-like growth factor- 1 and VEGF. ${ }^{61}$

\section{Patent ductus arteriosus}

In the CAP Trial, caffeine-treated infants required less pharmacologic intervention for patent ductus arteriosus (PDA) closure compared with placebo-treated infants $(29 \%$ vs. $38 \%, p<0.001)$. Also, only $4.5 \%$ of infants in the caffeine group required PDA ligation compared with $12.6 \%$ in the placebo group $(p<0.001){ }^{8}$ The beneficial effects of caffeine on PDA closure may be related to enhanced diuresis and antagonism of prostaglandin activity (also see sections on early treatment and higher doses). ${ }^{62}$

\section{Necrotizing enterocolitis}

Retrospective studies have reported conflicting results regarding a potential association between caffeine treatment and necrotizing enterocolitis (NEC). ${ }^{63,64}$ A post hoc analysis from a trial of caffeine therapy for AOP showed a trend toward more NEC in the caffeine compared with the placebo-treated group. ${ }^{65}$ Importantly, however, the randomized CAP Trial observed no differences in the rates of NEC between the treatment groups (6.3\% caffeine group, $6.7 \%$ placebo group, $p=0.63)^{8}$

Studies evaluating mesenteric blood flow velocities in preterm infants following loading doses of $25-50 \mathrm{mg} / \mathrm{kg}$ caffeine citrate showed a reduction in velocity. ${ }^{66,67} \mathrm{~A}$ study using a loading dose of $10 \mathrm{mg} / \mathrm{kg}$ caffeine base (equivalent to $20 \mathrm{mg} / \mathrm{kg}$ caffeine citrate), however, revealed no significant changes in superior mesenteric artery flow velocities. ${ }^{68}$ Unfortunately, there are no data assessing blood flow velocities during maintenance caffeine, and no studies assessing the clinical significance of decreased blood flow velocity. Based on all available clinical data including the CAP Trial, there is no evidence of a causal role for caffeine in the etiology of NEC.

\section{Inflammation}

A recent study evaluated modulation of cytokine release in response to caffeine exposure. ${ }^{69}$ Exposure of cord blood monocytes from full-term infants to caffeine at doses sufficient to achieve concentrations of $10-20 \mu \mathrm{g} / \mathrm{ml}$ decreased TNF- $\alpha$ and IL-10 secretion, but higher caffeine doses resulted in a pro-inflammatory response. An earlier study in infants being treated for AOP also concluded that caffeine concentrations $\geq 20 \mu \mathrm{g} / \mathrm{ml}$ were associated with a pro-inflammatory profile. ${ }^{70}$ The clinical significance of these apparent pro-inflammatory effects is unclear, especially considering the anti-inflammatory beneficial effects of caffeine on neurodevelopment and BPD. Also, animal studies demonstrate that caffeine promotes anti-inflammatory effects in the immature lung, especially in the setting of intra-amniotic infection. ${ }^{33,36,71}$ As discussed later, the studies reporting additive benefits of caffeine on multiple outcomes at higher doses are also indicative of an anti-inflammatory effect.

Other clinical effects

There were no differences in sleep duration or sleep-disordered breathing at 5-12 years of age in caffeine- vs. placebo-treated 
Table 2. Clinical benefits of beginning caffeine treatment before 3 days of age compared with treatment after 3 days of age ${ }^{a}$

- Decreased incidence of $\mathrm{BPD}^{\mathrm{b}}$, RR (cohort studies): $0.80,95 \% \mathrm{Cl} 0.66-0.96$; RR (RCTs): $0.67,95 \% \mathrm{Cl} 0.56-0.81$ (moderate quality)

- Decreased incidence of death or bronchopulmonary dysplasia (BPD), RR $0.84,95 \% \mathrm{Cl} 0.73-0.95$ (low quality)

- Decreased need to treat patent ductus arteriosus, RR $0.71,95 \% \mathrm{Cl} 0.60-0.84$ (low quality)

- Decreased incidence of intraventricular hemorrhage, RR $0.75,95 \% \mathrm{Cl} 0.67-0.83$ (low quality)

- Decreased need for therapy for retinopathy of prematurity, RR $0.85,95 \% \mathrm{Cl} 0.83-0.88$ (low quality)

- Decreased use of postnatal steroids, RR $0.65,95 \% \mathrm{Cl} 0.47-0.90$ (low quality)

- No effect on incidence of necrotizing enterocolitis, RR 1.03, 95\% Cl 0.90-1.18 (low quality)

${ }^{a}$ Risk ratios from meta-analysis ${ }^{88}$ of retrospective cohort studies ${ }^{24,85-87}$ unless otherwise indicated. Quality of evidence is based on the GRADE system ${ }^{104}$ ${ }^{b}$ Data from randomized, controlled trials (RCTs) as well as retrospective cohort studies

children from the CAP Trial. $^{72}$ Also, there were no significant differences in sleep duration or sleep quality during maintenance caffeine therapy compared to control infants, based on polysomnographic recordings at 33-34 weeks postmenstrual age $(\mathrm{PMA}) .^{73}$ In a prospective study of heart rate variability (HRV) in infants with AOP before and $1-2 \mathrm{~h}$ after receiving caffeine citrate loading dose of $15-20 \mathrm{mg} / \mathrm{kg}$, caffeine had no adverse effects on heart rate, blood pressure, or HRV. ${ }^{74}$ In a preterm lamb model assessing renal function after a caffeine loading dose of $40 \mathrm{mg} / \mathrm{kg}$ of caffeine base, the urine output was significantly higher after caffeine compared to controls for the 2-h duration of observation, but no significant changes in renal function were noted. ${ }^{75}$ In preterm infants studied $>12 \mathrm{~h}$ after starting caffeine, urine flow and creatinine clearance increased, and other renal functions improved, including urinary sodium excretion. ${ }^{76}$ In a retrospective study, preterm infants treated with caffeine in the first week of life were less likely to develop acute kidney injury, $17.8 \%$ vs. $43.6 \%$ in neonates not treated with caffeine, $p=0.002 .{ }^{77}$ Brainstem auditory neural processing is faster in infants receiving caffeine compared with controls, and caffeine appears to improve cortical processing of auditory stimuli as determined by event-related potentials. $^{78,79}$

\section{Side effects/toxicity}

Side effects of methylxanthine therapy include increased metabolic rate, increased oxygen consumption, tachycardia, cardiac dysrhythmias, jitteriness, and, at toxic levels, seizures. Case reports of accidental caffeine overdose in premature infants have described a variety of acute neurologic, cardiovascular, and metabolic abnormalities. ${ }^{80}$ One case report described a 28 -week infant who developed rhabdomyolysis while receiving standard caffeine dosing, with a caffeine level of $32.59 \mu \mathrm{g} / \mathrm{ml}{ }^{81}$ Other studies, however, have reported caffeine levels of $30-40 \mu \mathrm{g} / \mathrm{ml}$ without significant side effects. ${ }^{46,82}$

Caffeine increases cerebral cortical activity in preterm infants, but the clinical significance of this finding is unclear. ${ }^{83}$ The CAP Trial did not reveal any significant short- or long-term adverse effects of caffeine therapy in preterm infants. Caffeine-treated infants gained less weight during the first 3 weeks after randomization, but by 4 weeks, there was no difference in weight gain. ${ }^{8}$ At 18-21 months and at 5 years, the mean percentiles for weight, height, and head circumference did not differ between infants in the caffeine and placebo groups. ${ }^{37,40}$

\section{TIMING OF CAFFEINE INITIATION: BENEFITS OF EARLY TREATMENT}

In the CAP Trial, the benefits of caffeine were most significant when treatment was initiated within 3 days after birth. ${ }^{38}$ Several retrospective cohort studies subsequently observed that earlier initiation of caffeine therapy at $<3$ days was associated with improved outcomes as compared to initiation at $\geq 3$ days (Table 2). ${ }^{24,84-87}$ The largest of these studies evaluated outcomes in 62,056 VLBW infants and compared the outcomes between infants receiving early caffeine therapy at $<3$ days and infants not started on caffeine therapy until $\geq 3$ days. ${ }^{24}$ Early caffeine therapy was associated with a lower incidence of BPD ( $23.1 \%$ vs. $30.7 \%, p$ $<0.001)$, less treatment of PDA $(12.3 \%$ vs. $19 \%, p<0.001)$, lower incidence of intraventricular hemorrhage $(29.4 \%$ vs. $32.7 \%$, $p<0.001)$, and less therapy for ROP $(2.8 \%$ vs. $5 \%, p<0.001)$. Early caffeine was also associated with an increased incidence of death ( $4.5 \%$ in the early group vs. $3.7 \%$ in the late caffeine group, $p<$ 0.001 ), but this increase was attributed to survival bias since it only occurred in infants born $<24$ weeks, and the majority of these deaths occurred within the first 3 days after birth; infants born $<24$ weeks would thus have to survive more than 3 days in order to be eligible to receive late caffeine. Other retrospective studies and especially the prospective studies comparing the outcomes associated with early vs. late caffeine therapy did not find an increased incidence of death, but did confirm the association of decreased morbidities with early caffeine therapy. ${ }^{85,86,88,89}$

The results of the CAP Trial combined with these retrospective cohort and prospective studies provided moderate quality evidence for the beneficial effects of early initiation of caffeine therapy in VLBW infants. A subsequent randomized pilot study in 21 infants born $<29$ weeks' gestation evaluated the use of even earlier prophylactic caffeine citrate $(20 \mathrm{mg} / \mathrm{kg})$ started at $<2 \mathrm{~h}$ of age compared to initiation at $12 \mathrm{~h} .{ }^{90}$ There was a trend toward reduced intubation rates in the early caffeine group, but this did not reach statistical significance ( $27 \%$ vs. $70 \%, p=0.08)$. In infants $<30$ weeks gestation, a delivery room bolus of $10 \mathrm{mg} / \mathrm{kg}$ caffeine base in the first $7 \mathrm{~min}$ of age was associated with improved respiratory effort at birth compared to caffeine administration starting in the NICU, but the effects on clinical outcomes are unclear. ${ }^{91}$

In summary, studies of initiation of caffeine treatment at $<3$ days of life have generally shown positive benefits. ${ }^{88,89}$ One recent study, however, did raise significant concerns about very early, high-dose caffeine, and is discussed in the next section. ${ }^{92}$

\section{CAFFEINE DOSING: IS MORE BETTER?}

The FDA-approved caffeine for treatment of AOP in 1999 with a recommended loading dose of $20 \mathrm{mg} / \mathrm{kg}$ of caffeine citrate followed by a daily maintenance dose of $5 \mathrm{mg} / \mathrm{kg} .{ }^{93}$ Many centers are now using a maintenance dose range of $5-10 \mathrm{mg} / \mathrm{kg}$. Recent studies have reported using even higher maintenance doses and achieving incremental benefits compared with standard maintenance dosing without any adverse effects (Table 3). ${ }^{82,94,95} \mathrm{~A}$ randomized, double-blind trial of three different maintenance dosing regimens of caffeine citrate $(3,15$, and $30 \mathrm{mg} / \mathrm{kg})$ for periextubation management of infants born $<32$ weeks' gestation 
Table 3. Relationship between maintenance dose of caffeine citrate, clinical benefits, and side effects

\begin{tabular}{|c|c|c|}
\hline $\begin{array}{l}\text { Maintenance dose of caffeine } \\
\text { citrate }^{a}\end{array}$ & Established clinical benefits & Potential side effects \\
\hline $5-10 \mathrm{mg} / \mathrm{kg} /$ day & $\begin{array}{l}\text { 1) Treats apnea of prematurity } \\
\text { 2) Facilitates extubation, with shorter duration of intubation and } \\
\text { non-invasive respiratory support } \\
\text { 3) Reduces incidence of BPD/CLD } \\
\text { 4) Decreases the need for treatment of PDA } \\
\text { 5) Reduces severity of ROP } \\
\text { 6) Improves motor function and visual perception at 5-year } \\
\text { follow-up }\end{array}$ & $\begin{array}{l}\text { 1) Generalized CNS stimulant: causes irritability, } \\
\text { jitteriness, tremors, and hypertonia, } \\
\text { 2) Cardiovascular effects: tachycardia and increased } \\
\text { blood pressure } \\
\text { 3) Decreased weight gain in first } 3 \text { weeks after } \\
\text { treatment initiation } \\
\text { 4) No known long-term adverse effects }\end{array}$ \\
\hline $20 \mathrm{mg} / \mathrm{kg}$ & $\begin{array}{l}\text { Compared with standard dosing: } \\
\text { 1) More effective in reducing apnea } \\
\text { 2) Reduces extubation failure } \\
\text { 3) Reduces duration of mechanical ventilation } \\
\text { 4) Possible improvement in early neurodevelopmental } \\
\text { outcomes }\end{array}$ & $\begin{array}{l}\text { 1) Longer time to regain birth weight } \\
\text { 2) Possible increase in feeding intolerance } \\
\text { 3) Increased incidence of tachycardia in some } \\
\text { studies }\end{array}$ \\
\hline
\end{tabular}

revealed no difference in extubation failure between groups, but infants in the two higher-dose groups had significantly less apnea compared with the lowest-dose group. ${ }^{82}$ Another trial comparing maintenance doses of 20 vs. $5 \mathrm{mg} / \mathrm{kg} / \mathrm{day}$ of caffeine citrate for peri-extubation management did show a significant reduction in extubation failure in the high-dose group (15\% vs. $29.8 \%$; relative risk $0.51[0.31-0.85]) .{ }^{95}$ Also, in the subgroup of infants with a gestational age $<28$ weeks at birth, the duration of mechanical ventilation was significantly less in the high-dose group. One- and two-year follow-up of these cohorts revealed no significant differences in developmental outcomes. ${ }^{82,96}$ A recent trial compared high dose (caffeine citrate loading dose of $40 \mathrm{mg} / \mathrm{kg}$, maintenance $20 \mathrm{mg} / \mathrm{kg} /$ day) to low dose (loading $20 \mathrm{mg} / \mathrm{kg}$, maintenance $10 \mathrm{mg} / \mathrm{kg} / \mathrm{day}$ ) for AOP at $<32$ weeks' gestation; the higher-dose cohort showed a significant reduction in extubation failure, frequency of apnea, and days of documented apnea compared with the standard dose regimen. ${ }^{94}$ The positive results of these trials, combined with minimal side effects from the high-dose regimens, have led many international centers to routinely use maintenance caffeine citrate doses as high as $20 \mathrm{mg} /$ $\mathrm{kg} / \mathrm{day}$, but maintenance doses in excess of $10 \mathrm{mg} / \mathrm{kg} / \mathrm{day}$ are rare in the United States.

The studies using caffeine doses higher than $10 \mathrm{mg} / \mathrm{kg} /$ day have not focused on the first 3 days of age. A recent randomized controlled trial investigated the potential neuroprotective benefits of caffeine in preterm infants using a very high-dose regimen starting at $<24 \mathrm{~h}$ of age in infants born at $\leq 30$ weeks' gestation. ${ }^{92}$ Infants randomized to high-dose caffeine citrate $(80 \mathrm{mg} / \mathrm{kg}$ over $36 \mathrm{~h})$ were compared with a standard dose regimen of $30 \mathrm{mg} / \mathrm{kg}$ over $36 \mathrm{~h}$. In a post hoc analysis, the highdose group showed an unanticipated finding of increased incidence of cerebellar hemorrhage ( $36 \%$ vs. $10 \%, p=0.03$ ), subtle neurobehavioral differences at term equivalent age, and a trend toward increased seizure incidence and burden. ${ }^{92,97}$ Despite these adverse findings, however, brain MRIs at term equivalent age did not reveal any differences between the groups in brain growth as measured by brain metrics and volumes, nor in white matter injury as assessed by apparent diffusion coefficient or fractional anisotropy, and developmental outcomes at 2 years of age did not differ between the two groups. ${ }^{92}$ Although these results raise potential concerns about the use of very high-dose caffeine at a very early age in extremely preterm infants, it is important to note that none of the studies reporting a favorable benefit-to-risk ratio for highdose caffeine used such a high dose at such an early age.

\section{SHOULD CAFFEINE CONCENTRATIONS BE MEASURED?}

Caffeine levels are rarely performed today unless there is a persistence of symptoms or concern for toxicity. A recent study of plasma caffeine concentrations, however, suggested that higher cumulative concentrations of caffeine may offer incremental benefits. This single-center, retrospective study correlated higher-average caffeine concentrations $(\geq 14.5 \mu \mathrm{g} / \mathrm{ml})$ with reduced chronic lung disease rates as well as reduced duration of ventilation, length of stay, use of oxygen at discharge, and total hospital charges per patient. ${ }^{98}$ If these findings are confirmed prospectively, there may be renewed interest in monitoring caffeine levels. The standard caffeine maintenance dosing regimen typically achieves blood concentrations of $8-20 \mu \mathrm{g} / \mathrm{ml}$ in infants $<32$ weeks PMA, but preterm infants appear to safely tolerate caffeine concentrations as high as $50-84 \mu \mathrm{g} / \mathrm{ml}$ even at younger PMA. ${ }^{11,82,99}$ A major drawback in monitoring caffeine levels is the need for blood sampling, but studies show good correlation between salivary and plasma caffeine concentrations. ${ }^{100-102}$ The most recent study comparing salivary and plasma caffeine concentrations found the mean of the differences $(95 \%$ $\mathrm{Cl})$ between plasma and salivary concentrations to be -0.18 $(-1.90,1.54)$, showing no significant bias between the two measures. ${ }^{101}$ If further studies confirm incremental benefits with higher concentrations of caffeine, salivary sampling would be a valid alternative to blood for measuring caffeine concentrations to optimize caffeine dosing.

\section{OPTIMUM DURATION OF CAFFEINE TREATMENT: WHEN TO STOP?}

Routine caffeine treatment is typically discontinued by 33-35 weeks PMA following cessation of apnea-related symptoms. Median PMA at last dose in the CAP Trial was 34.4 weeks (IQR 33.0-35.9). ${ }^{8}$ Significant amounts of intermittent hypoxia $(\mathrm{IH})$ persist after stopping caffeine treatment, and caffeine reduces the extent of $\mathrm{IH}^{46,48}$ However, unless and until studies confirm that persisting $\mathrm{IH}$ to term equivalent age or beyond is associated with acute injury and longer term adverse consequences ameliorated with persisting caffeine treatment, there is no clinical indication for extending the duration of caffeine treatment in VLBW infants beyond the current clinical routine of 33-35 weeks PMA.

There is no consensus as to the optimum duration of observation after stopping caffeine treatment before it is safe to discharge home. The recent American Academy of Pediatrics 
Statement summarizes the relevant issues and available evidencebased recommendations. ${ }^{103}$

\section{CONCLUSION}

The first study showing efficacy of caffeine for treatment of apnea in preterm infants was published 40 years ago. ${ }^{6}$ The groundbreaking CAP Trial confirmed the safety and additional significant benefits of caffeine therapy, including a shorter duration of intubation and respiratory support, reduced incidence of BPD, decreased need for treatment of PDA, reduced severity of ROP, improved motor function, and lower rates of developmental coordination disorder. $8,37,38,40,44,49$ More recent studies have yielded new insights regarding mechanisms, and delineated the benefits of initiation of therapy before 3 days of age and higher maintenance doses to achieve incremental beneficial effects. The aggregate data have established the safety and efficacy of caffeine therapy in preterm infants, and have resulted in caffeine being one of the most widely used NICU pharmacologic agents. Although placebo-controlled trials are no longer justifiable, additional prospective studies are warranted to further clarify underlying mechanisms, to determine the optimal dose and net benefits of early prophylactic caffeine, and to determine how long to continue caffeine therapy to achieve the optimum benefit-torisk ratio.

\section{DISCLAIMER}

The views expressed in this article are those of the authors and do not necessarily reflect the official policy or position of the Department of the Army, Department of Defense, nor the U.S. Government. Some authors are a military service member or a U.S. Government employee. This work was prepared as part of their official duties. Title 17 U.S.C. 105 provides that 'Copyright protection under this title is not available for any work of the United States Government.' Title 17 U.S.C. 101 defines a United States Government work as a work prepared by a military service member or employee of the United States Government as part of that person's official duties.

\section{ADDITIONAL INFORMATION}

Competing interests: The authors declare no competing interests.

Publisher's note: Springer Nature remains neutral with regard to jurisdictional claims in published maps and institutional affiliations.

\section{REFERENCES}

1. Finer, N. N., Higgins, R., Kattwinkel, J. \& Martin, R. J. Summary proceedings from the apnea-of-prematurity group. Pediatrics 117, S47-S51 (2006).

2. Horne, R. S. et al. The longitudinal effects of persistent apnea on cerebral oxygenation in infants born preterm. J. Pediatr. 182, 79-84 (2017).

3. Kuzemko, J. A. \& Paala, J. Apnoeic attacks in the newborn treated with aminophylline. Arch. Dis. Child 48, 404-406 (1973).

4. Shannon, D. C. et al. Prevention of apnea and bradycardia in low-birthweight infants. Pediatrics 55, 589-594 (1975).

5. Uauy, R., Shapiro, D. L., Smith, B. \& Warshaw, J. B. Treatment of severe apnea in prematures with orally administered theophylline. Pediatrics 55, 595-598 (1975).

6. Aranda, J. V., Gorman, W., Bergsteinsson, H. \& Gunn, T. Efficacy of caffeine in treatment of apnea in the low-birth-weight infant. J. Pediatr. 90, 467-472 (1977).

7. Aranda, J. V. et al. Pharmacokinetic profile of caffeine in the premature newborn infant with apnea. J. Pediatr. 94, 663-668 (1979).

8. Schmidt, B. et al. Caffeine therapy for apnea of prematurity. N. Engl. J. Med 354, 2112-2121 (2006).

9. Costantini, L., D'llario, J., Moddemann, D., Penner, K. \& Schmidt, B. Accuracy of Bayley scores as outcome measures in trials of neonatal therapies. JAMA Pediatr. 169, 188-189 (2015).

10. Bhatt-Mehta, V. \& Schumacher, R. E. Treatment of apnea of prematurity. Paediatr. Drugs 5, 195-210 (2003).
11. Dobson, N. R. \& Hunt, C. E. Pharmacology review: caffeine use in neonates: indications, pharmacokinetics, clinical effects, outcomes. Neoreviews 14, e540-e550 (2013).

12. Fredholm, B. B., Battig, K., Holmen, J., Nehlig, A. \& Zvartau, E. E. Actions of caffeine in the brain with special reference to factors that contribute to its widespread use. Pharmacol. Rev. 51, 83-133 (1999).

13. Parikka, V. et al. The effect of caffeine citrate on neural breathing pattern in preterm infants. Early Human. Dev. 91, 565-568 (2015).

14. Rigatto, H., Desai, U., Leahy, F., Kalapesi, Z. \& Cates, D. The effect of $2 \% \mathrm{CO} 2$, $100 \%$ O2, theophylline and 15\% O2 on "inspiratory drive" and "effective" timing in preterm infants. Early Hum. Dev. 5, 63-70 (1981).

15. Marchal, F., Bairam, A. \& Vert, P. Neonatal apnea and apneic syndromes. Clin. Perinatol. 14, 509-529 (1987).

16. Dux, E., Fastbom, J., Ungerstedt, U., Rudolphi, K. \& Fredholm, B. B. Protective effect of adenosine and a novel xanthine derivative propentofylline on the cell damage after bilateral carotid occlusion in the gerbil hippocampus. Brain Res 516, 248-256 (1990).

17. Goda, H. et al. Modulation of ischemia-evoked release of excitatory and inhibitory amino acids by adenosine A1 receptor agonist. Eur. J. Pharmacol. 357, 149-155 (1998).

18. Rudolphi, K. A., Schubert, P., Parkinson, F. E. \& Fredholm, B. B. Neuroprotective role of adenosine in cerebral ischaemia. Trends Pharmacol. Sci. 13, 439-445 (1992).

19. Bairam, A., Boutroy, M. J., Badonnel, Y. \& Vert, P. Theophylline versus caffeine: comparative effects in treatment of idiopathic apnea in the preterm infant. $J$. Pediatr. 110, 636-639 (1987).

20. Brouard, C. et al. Comparative efficacy of theophylline and caffeine in the treatment of idiopathic apnea in premature infants. Am. J. Dis. Child 139, 698-700 (1985).

21. Henderson-Smart D. J. \& De Paoli, A. G. Methylxanthine treatment for apnoea in preterm infants. Cochrane Database Syst. Rev. CD000140 (2010).

22. Scanlon, J. E. et al. Caffeine or theophylline for neonatal apnoea? Arch. Dis. Child 67, 425-428 (1992).

23. Skouroliakou, M., Bacopoulou, F. \& Markantonis, S. L. Caffeine versus theophylline for apnea of prematurity: a randomised controlled trial. J. Paediatr. Child Health 45, 587-592 (2009).

24. Dobson, N. R. et al. Trends in caffeine use and association between clinical outcomes and timing of therapy in very low birth weight infants. J. Pediatr. 164, 992 (2014).

25. Bucher, H. U. \& Duc, G. Does caffeine prevent hypoxaemic episodes in premature infants? A randomized controlled trial. Eur. J. Pediatr. 147, 288-291 (1988).

26. Henderson-Smart D. J. \& De Paoli, A. G. Prophylactic methylxanthine for prevention of apnoea in preterm infants. Cochrane Database Syst. Rev. CD000432 (2010).

27. Abu Jawdeh, E. G. et al. Methylxanthine use for apnea of prematurity among an international cohort of neonatologists. J. Neonatal Perinat. Med 6, 251-256 (2013).

28. Armanian, A. M., Iranpour, R., Faghihian, E. \& Salehimehr, N. Caffeine administration to prevent apnea in very premature infants. Pediatr. Neonatol. 57, 408-412 (2016).

29. Henderson-Smart D. J. \& Davis P. G. Prophylactic methylxanthines for endotracheal extubation in preterm infants. Cochrane Database Syst. Rev. CD000139 (2010).

30. Kassim, Z., Greenough, A. \& Rafferty, G. F. Effect of caffeine on respiratory muscle strength and lung function in prematurely born, ventilated infants. Eur. J. Pediatr. 168, 1491-1495 (2009).

31. Kraaijenga, J. V., Hutten, G. J., de Jongh, F. H. \& van Kaam, A. H. The effect of caffeine on diaphragmatic activity and tidal volume in preterm infants. J. Pediatr. 167, 70-75 (2015).

32. Doyle, L. W., Ranganathan, S. \& Cheong, J. L. Y. Neonatal caffeine treatment and respiratory function at 11 years in children under $1,251 \mathrm{~g}$ at birth. Am. J. Respir. Crit. Care Med. 196, 1318-1324 (2017).

33. Jing, X. G. et al. Caffeine ameliorates hyperoxia-induced lung injury by protecting $\mathrm{GCH} 1$ function in neonatal rat pups. Pediatr. Res. 82, 483-489 (2017).

34. Rath, P. et al. Caffeine administration modulates TGF-beta signaling but does not attenuate blunted alveolarization in a hyperoxia-based mouse model of bronchopulmonary dysplasia. Pediatr. Res. 81, 795-805 (2017).

35. Tiwari, K. K., Chu, C., Couroucli, X., Moorthy, B. \& Lingappan, K. Differential concentration-specific effects of caffeine on cell viability, oxidative stress, and cell cycle in pulmonary oxygen toxicity in vitro. Biochem. Biophys. Res. Commun. 450, 1345-1350 (2014)

36. Weichelt, U. et al. Prevention of hyperoxia-mediated pulmonary inflammation in neonatal rats by caffeine. Eur. Respir. J. 41, 966-973 (2013). 
37. Schmidt, B. et al. Long-term effects of caffeine therapy for apnea of prematurity. N. Engl. J. Med. 357, 1893-1902 (2007).

38. Davis, P. G. et al. Caffeine for apnea of prematurity trial: benefits may vary in subgroups. J. Pediatr. 156, 382-387 (2010).

39. Dukhovny, D. et al. Economic evaluation of caffeine for apnea of prematurity. Pediatrics 127, e146-e155 (2011).

40. Schmidt, B. et al. Survival without disability to age 5 years after neonatal caffeine therapy for apnea of prematurity. JAMA 307, 275-282 (2012).

41. de Kieviet, J. F., Piek, J. P., Aarnoudse-Moens, C. S. \& Oosterlaan, J. Motor development in very preterm and very low-birth-weight children from birth to adolescence: a meta-analysis. JAMA 302, 2235-2242 (2009).

42. Doyle, L. W. et al. Reduction in developmental coordination disorder with neonatal caffeine therapy. J. Pediatr. 165, 356-359.e2 (2014).

43. Williams, J., Lee, K. J. \& Anderson, P. J. Prevalence of motor-skill impairment in preterm children who do not develop cerebral palsy: a systematic review. Dev. Med Child Neurol. 52, 232-237 (2010).

44. Schmidt, B. et al. Academic performance, motor function, and behavior 11 years after neonatal caffeine citrate therapy for apnea of prematurity: an 11-year follow-up of the CAP randomized clinical trial. JAMA Pediatr. 171, 564-572 (2017).

45. Di Fiore, J. M. et al. A higher incidence of intermittent hypoxemic episodes is associated with severe retinopathy of prematurity. J. Pediatr. 157, 69-73 (2010).

46. Dobson, N. R. et al. Caffeine decreases intermittent hypoxia in preterm infants nearing term-equivalent age. J. Perinatol. 37, 1135-1140 (2017).

47. Martin, R. J., Wang, K., Koroglu, O., Di Fiore, J. \& Kc, P. Intermittent hypoxic episodes in preterm infants: do they matter? Neonatology 100, 303-310 (2011).

48. Rhein, L. M. et al. Effects of caffeine on intermittent hypoxia in infants born prematurely: a randomized clinical trial. JAMA Pediatr. 168, 250-257 (2014).

49. Doyle, L. W. et al. Caffeine and brain development in very preterm infants. Ann. Neurol. 68, 734-742 (2010).

50. Pogribna, $U$. et al. Perinatal clinical antecedents of white matter microstructural abnormalities on diffusion tensor imaging in extremely preterm infants. PloS ONE 8, e72974 (2013).

51. Supcun, S., Kutz, P., Pielemeier, W. \& Roll, C. Caffeine increases cerebral cortical activity in preterm infants. J. Pediatr. 156, 490-491 (2010).

52. Back, S. A. et al. Protective effects of caffeine on chronic hypoxia-induced perinatal white matter injury. Ann. Neurol. 60, 696-705 (2006).

53. Connolly, S. \& Kingsbury, T. J. Caffeine modulates CREB-dependent gene expression in developing cortical neurons. Biochem Biophys. Res Commun. 397, 152-156 (2010).

54. Gaytan, S. P. \& Pasaro, R. Neonatal caffeine treatment up-regulates adenosine receptors in brainstem and hypothalamic cardio-respiratory related nuclei of rat pups. Exp. Neurol. 237, 247-259 (2012)

55. Turner, C. P. et al. A1 adenosine receptors mediate hypoxia-induced ventriculomegaly. Proc. Natl Acad. Sci. USA 100, 11718-11722 (2003).

56. Winerdal, M., et al. Single dose caffeine protects the neonatal mouse brain against hypoxia ischemia. PLOS ONE 12, e0170545 (2017).

57. Endesfelder, S., et al. Neuroprotection by caffeine in hyperoxia-induced neonatal brain injury. Int. J. Mol. Sci. 18, (2017) https://doi.org/10.3390/ijms18010187.

58. Atik, A. et al. Caffeine for apnea of prematurity: effects on the developing brain. Neurotoxicology 58, 94-102 (2017).

59. Chen, J. F. et al. Adenosine receptors and caffeine in retinopathy of prematurity. Mol. Asp. Med. 55, 118-125 (2017).

60. Zhang, S. et al. Caffeine preferentially protects against oxygen-induced retinopathy. FASEB J. 31, 3334-3348 (2017)

61. Aranda, J. V. et al. Pharmacologic synergism of ocular ketorolac and systemic caffeine citrate in rat oxygen-induced retinopathy. Pediatr. Res. 80, 554-565 (2016).

62. Manku, M. S. \& Horrobin, D. F. Chloroquine, quinine, procaine, quinidine, tricyclic antidepressants, and methylxanthines as prostaglandin agonists and antagonists. Lancet 2, 1115-1117 (1976).

63. Cox, C., Hashem, N. G., Tebbs, J., Bookstaver, P. B. \& Iskersky, V. Evaluation of caffeine and the development of necrotizing enterocolitis. J. Neonatal Perinatal Med. 8, 339-347 (2015).

64. Lampkin, S. J. et al. Association between caffeine citrate exposure and necrotizing enterocolitis in preterm infants. Am. J. Health-Syst. Pharm. 70, 603-608 (2013).

65. Erenberg, A. et al. Caffeine citrate for the treatment of apnea of prematurity: a double-blind, placebo-controlled study. Pharmacotherapy 20, 644-652 (2000).

66. Hoecker, C., Nelle, M., Poeschl, J., Beedgen, B. \& Linderkamp, O. Caffeine impairs cerebral and intestinal blood flow velocity in preterm infants. Pediatrics 109 784-787 (2002).

67. Natarajan, G., Lulic-Botica, M. \& Aranda, J. V. Clinical pharmacology of caffeine in the newborn. NeoReviews 8, 213-221 (2007).
68. Soraisham, A. S., Elliott, D. \& Amin, H. Effect of single loading dose of intravenous caffeine infusion on superior mesenteric artery blood flow velocities in preterm infants. J. Paediatr. Child Health 44, 119-121 (2008).

69. Chavez-Valdez, R., Ahlawat, R., Wills-Karp, M. \& Gauda, E. B. Mechanisms of modulation of cytokine release by human cord blood monocytes exposed to high concentrations of caffeine. Pediatr. Res. 80, 101-109 (2016).

70. Chavez Valdez, R. et al. Correlation between serum caffeine levels and changes in cytokine profile in a cohort of preterm infants. J. Pediatr. 158, 57-64 (2011). $64 \mathrm{e} 51$.

71. Koroglu, O. A. et al. Anti-inflammatory effect of caffeine is associated with improved lung function after lipopolysaccharide-induced amnionitis. Neonatology 106, 235-240 (2014).

72. Marcus, C. L. et al. Long-term effects of caffeine therapy for apnea of prematurity on sleep at school age. Am. J. Respir. Crit. Care Med. 190, 791-799 (2014).

73. Curzi-Dascalova, L., Aujard, Y., Gaultier, C. \& Rajguru, M. Sleep organization is unaffected by caffeine in premature infants. J. Pediatr. 140, 766-771 (2002).

74. Ulanovsky, I., Haleluya, N. S., Blazer, S. \& Weissman, A. The effects of caffeine on heart rate variability in newborns with apnea of prematurity. J. Perinatol. 34, 620-623 (2014).

75. Crossley, K. J. et al. Effects of caffeine on renal and pulmonary function in preterm newborn lambs. Pediatr. Res. 72, 19-25 (2012).

76. Gillot, I., Gouyon, J. B. \& Guignard, J. P. Renal effects of caffeine in preterm infants. Biol. Neonate 58, 133-136 (1990).

77. Carmody, J. B., Harer, M. W., Denotti, A. R., Swanson, J. R. \& Charlton, J. R. Caffeine exposure and risk of acute kidney injury in a retrospective cohort of very low birth weight neonates. J. Pediatr. 172, 63 (2016).

78. Chen, Y. J., Liou, C. S., Tsai, C. H. \& Yeh, T. F. Effect of aminophylline on brain stem auditory evoked potentials in preterm infants. Arch. Dis. Child Fetal Neonatal Ed. 71, F20-F23 (1994).

79. Maitre, N. L. et al. Effects of caffeine treatment for apnea of prematurity on cortical speech-sound differentiation in preterm infants. J. Child Neurol. 30, 307-313 (2015).

80. Ergenekon, E., Dalgic, N., Aksoy, E., Koc, E. \& Atalay, Y. Caffeine intoxication in a premature neonate. Paediatr. Anaesth. 11, 737-739 (2001).

81. Nakaoka, S., Kawasaki, Y., Inomata, S., Makimoto, M. \& Yoshida, T. Caffeine toxicity in a preterm neonate. Pediatr. Neonatol. 58, 380-381 (2017).

82. Steer, P. A. et al. Periextubation caffeine in preterm neonates: a randomized dose response trial. J. Paediatr. Child Health 39, 511-515 (2003).

83. Hassanein, S. M., Gad, G. I., Ismail, R. I. \& Diab, M. Effect of caffeine on preterm infants' cerebral cortical activity: an observational study. J. Matern Fetal Neonatal Med 28, 2090-2095 (2015).

84. Gupte, A. S., Gupta, D., Ravichandran, S., Ma, M. M. \& Chouthai, N. S. Effect of early caffeine on neurodevelopmental outcome of very low-birth weight newborns. J. Matern Fetal Neonatal Med 29, 1233-1237 (2016).

85. Lodha, A. et al. Association of early caffeine administration and neonatal outcomes in very preterm neonates. JAMA Pediatr. 169, 33-38 (2015).

86. Patel, R. M., Leong, T., Carlton, D. P. \& Vyas-Read, S. Early caffeine therapy and clinical outcomes in extremely preterm infants. J. Perinatol. 33, 134-140 (2013).

87. Taha, D. et al. Early caffeine therapy for prevention of bronchopulmonary dysplasia in preterm infants. J. Matern. Fetal Neonatal Med. 27, 1698-1702 (2014).

88. Kua, K. P. \& Lee, S. W. H. Systematic review and meta-analysis of clinical outcomes of early caffeine therapy in preterm neonates. Br. J. Clin. Pharmacol. 83, 180-191 (2017).

89. Park, H. W. et al. Early caffeine use in very low birth weight infants and neonatal outcomes: a systematic review and meta-analysis. J. Korean Med. Sci. 30, 1828-1835 (2015)

90. Katheria, A. C. et al. A pilot randomized controlled trial of early versus routine caffeine in extremely premature infants. Am. J. Perinatol. 32, 879-885 (2015).

91. Dekker, J. et al. Caffeine to improve breathing effort of preterm infants at birth: a randomized controlled trial. Pediatr. Res. 82, 290-296 (2017).

92. McPherson, C., Neil, J. J., Tjoeng, T. H., Pineda, R. \& Inder, T. E. A pilot randomized trial of high-dose caffeine therapy in preterm infants. Pediatr. Res. 78, 198-204 (2015).

93. Leon, A. E., Michienzi, K., Ma, C. X. \& Hutchison, A. A. Serum caffeine concentrations in preterm neonates. Am. J. Perinatol. 24, 39-47 (2007).

94. Mohammed, S. et al. High versus low-dose caffeine for apnea of prematurity: a randomized controlled trial. Eur. J. Pediatr. 174, 949-956 (2015).

95. Steer, P. et al. High dose caffeine citrate for extubation of preterm infants: a randomised controlled trial. Arch. Dis. Child Fetal Neonatal Ed. 89, F499-F503 (2004).

96. Gray, P. H. et al. Caffeine citrate for very preterm infants: effects on development, temperament and behaviour. J. Paediatr. Child Health 47, 167-172 (2011). 
Caffeine: an evidence-based success story in VLBW pharmacotherapy NR Dobson and CE Hunt

97. Vesoulis, Z. A., McPherson, C., Neil, J. J., Mathur, A. M. \& Inder, T. E. Early highdose caffeine increases seizure burden in extremely preterm neonates: a preliminary study. J. Caffeine Res. 6, 101-107 (2016).

98. Alur, P., Bollampalli, V., Bell, T., Hussain, N. \& Liss, J. Serum caffeine concentrations and short-term outcomes in premature infants of $<=29$ weeks of gestation. J. Perinatol. 35, 434-438 (2015).

99. Natarajan, G., Botica, M. L., Thomas, R. \& Aranda, J. V. Therapeutic drug monitoring for caffeine in preterm neonates: an unnecessary exercise? Pediatrics 119, 936-940 (2007).

100. de Wildt, S. N. et al. Use of saliva in therapeutic drug monitoring of caffeine in preterm infants. Ther. Drug Monit. 23, 250-254 (2001).
101. Dobson, N. R. et al. Salivary caffeine concentrations are comparable to plasma concentrations in preterm infants receiving extended caffeine therapy. Br. J. Clin. Pharmacol. 82, 754-761 (2016).

102. Lee, T. C., Charles, B. G., Steer, P. A. \& Flenady, V. J. Saliva as a valid alternative to serum in monitoring intravenous caffeine treatment for apnea of prematurity. Ther. Drug Monit. 18, 288-293 (1996).

103. Eichenwald, E. C. \& Newborn, C. F. Apnea of prematurity. Pediatrics 137, 1-7 (2016).

104. Guyatt, G. H. et al. GRADE: an emerging consensus on rating quality of evidence and strength of recommendations. BMJ 336, 924-926 (2008). 